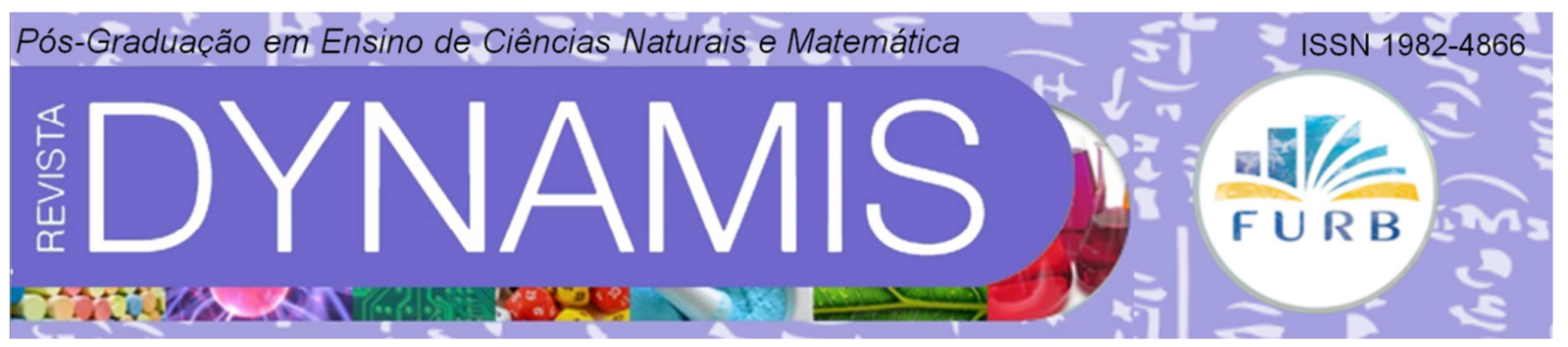

\title{
EFEITOS DE COLONIALIDADE NO CURRÍCULO DE CIÊNCIAS DO ENSINO SECUNDÁRIO EM TIMOR-LESTE
}

Effects of coloniality of ccience curriculum in the Secondary Educationin East Timor

\begin{abstract}
Alessandro Tomaz Barbosa
Doutorando do Programa de Pós-Graduação em Educação Científica e Tecnológica - PPGECT/UFSC Universidade Federal de Santa Catarina alessandro.tomaz3@gmail.com
\end{abstract}

\section{Suzani Cassiani}

Departamento de Metodologia de Ensino

Programa de Pós-Graduação em Educação Científica e Tecnológica - PPGECT/UFSC

Universidade Federal de Santa Catarina

suzanicassiani@gmail.com 


\title{
Resumo
}

Este artigo tem como objetivo investigar na literatura e nos documentos nacionais do TimorLeste, aspectos referentes ao contexto histórico da construção curricular do Ensino Secundário Geral e ainda realizar algumas reflexões sobre a implantação do mesmo. Adotamos nesse trabalho, alguns referenciais teóricos baseados nas teorias do currículo, colonialidade e outros estudos latino-americanos que relacionam ciência, tecnologia e sociedade e teorias dos discursos para refletir e discutir a construção curricular do ESG. Os resultados sinalizam que construção desse currículo se deu principalmente por instituições portuguesas responsáveis e teve pouca participação dos timorenses, caracterizando uma construção curricular de cima para baixo. A partir disso, conclui-se a necessidade de aprofundar no contexto timorense aspectos da transnacionalização do currículo e estudos de descolonização do saber, para que possamos construir saídas mais emancipadoras.

Palavras-chave: Transnacionalização do Currículo. Descolonização do saber/poder. Epistemologias do Sul.

\begin{abstract}
This article aims to investigate the literature and national East Timor documents, aspects related to the historical context of curriculum development on ESG, as well as some reflections of its implementation. We have adopted in this paper, some theoretical frameworks based on curriculum theories, studies on coloniality and another Latin American studies that link science, technology and society and theories of discourse to reflect and discuss the construction of ESG curriculum. The results indicate that the construction of this curriculum is given mainly responsible Portuguese institutions and had little participation of the Timorese, with a curriculum construction from top to bottom. From there, it follows the need to deepen aspects silenced on the Timorese context, transnationalisation curriculum and the decolonization of knowledgestudies, so that we can build more emancipatory outputs.
\end{abstract}

Keywords: Transnationalization Curriculum. Decolonization of knowledge/power. Southern epistemology. 


\section{INTRODUÇÃO}

Neste artigo buscamos investigar na literatura e nos documentos nacionais do TimorLeste, aspectos referentes ao contexto histórico da construção curricular do Ensino Secundário Geral (ESG) e também apresentar algumas reflexões sobre a implantação do mesmo. Pretendemos iniciar algumas discussões tendo em mente a seguinte questão: Como se dá o processo de colonialidade do saber/poder pelo currículo? Nesse cenário, nossa meta é refletir sobre o contexto timorense, tanto baseados em reflexões sobre a colonialidade do saber/poder (CASTRO-GOMEZ, 2007; MIGNOLO, 2003; QUIJANO, 2010; SANTOS; MENESES, 2010), como provocações para possíveis auto críticas desses olhares e quem sabe certa superação dos mesmos.

Nessa direção, organizamos o trabalho em dois tópicos. No primeiro tópico, Condições de Produção Curricular do Ensino Secundário Geral, apresentamos primeiramente alguns apontamentos do Plano do Ministério da Educação (2013-2017), que tem como uma de suas metas, a avaliação e implementação do currículo do ESG. Além disso, ressaltamos a construção dicotômica e fragmentada do currículo do ESG, a qual organiza duas frentes: o componente "Ciências e Tecnologias" e o componente "Ciências Sociais e Humanidades". Somando-se a esse quadro, temos a falta da participação de professores timorenses na elaboração do currículo do ESG, resultando em uma proposta curricular distante do seu contexto.

No segundo tópico, intitulado Processos de Colonialidade pelo Currículo, apresentamos alguns referenciais teóricos baseados nas teorias do currículo, colonialidade e outros estudos latino-americanos que relacionam ciência, tecnologia e sociedade e teorias do discurso, para debater a implementação do currículo do ESG no contexto timorense.

Por último, apresentamos algumas considerações, apontando a importância dos professores timorenses de Biologia, desenvolverem a sua autonomia docente, de forma que possam agir criticamente durante a sua atuação como professores nas escolas de ensino secundário.

\section{CONDIÇÕES DE PRODUÇÃO CURRICULAR DO ENSINO SECUNDÁRIO GERAL}

Em 2010, o Ministério da Educação de Timor-Leste solicitou o apoio da Fundação Calouste Gulbenkian (FCG) para proceder à reestruturação curricular do ESG no país. Para efeito, a FCG e o Instituto Português de Apoio ao Desenvolvimento (IPAD), com o apoio técnico da Universidade de Aveiro, prepararam e apresentaram conjuntamente ao Fundo da Língua Portuguesa um projeto, que foi aprovado para financiamento (MARTINS, 2013).

No plano curricular elaborado por essas instituições foram apresentados, descritos e caracterizados três componentes (componente de formação geral, componente Ciência e Tecnologia e componente Ciências Sociais e Humanidades), sendo enumeradas as suas finalidades formativas gerais.

O plano curricular do ESG (2011) foi organizado contendo dois percursos paralelos alternativos, um em "Ciência e Tecnologia" e outro em "Ciências Sociais e Humanidades", cada um deles constituído por cinco disciplinas específicas. 
O plano integra ainda, um componente de formação geral, comum a ambas as vias, da qual fazem parte oito disciplinas, nos $10^{\circ}$ e $11^{\circ}$ anos, e sete no $12^{\circ}$ (quadro 1 ).

Quadro 1 - Organização das disciplinas no currículo do Ensino Secundário Geral em Timor-Leste

\begin{tabular}{|c|l|l|}
\hline $\begin{array}{c}\text { Componente em } \\
\text { Ciências e Tecnologias }\end{array}$ & \multicolumn{1}{|c|}{ Componente Geral } & $\begin{array}{c}\text { Componente Ciências } \\
\text { Sociais e Humanidades }\end{array}$ \\
\hline 1. Física & 1. Tétum & 1. Geografia \\
2. Química & 2. Português & 2. História \\
3. Biologia & 3. Inglês & 3. Sociologia \\
4. Geologia & 4. Indonésio & 4. Temas de Literatura e \\
5. Matemática & 5. Cidadania e Desenvolvimento & Cultura \\
& Social & Economia e Métodos \\
& 6. Tecnologias Multimídia & Quantitativos \\
& 7. Religião e Moral & \\
\hline
\end{tabular}

Fonte: Elaborado pelos autores

O Plano Curricular do ESG (2011) pretende ser um instrumento organizador do trabalho das escolas, permitindo aos alunos escolherem uma das duas vias de formação: "Ciências e Tecnologias" ou "Ciências Sociais e Humanidades", que os habilite a entrarem no mercado de trabalho ou a prosseguirem estudos superiores. O currículo configurado dessa forma admite que os alunos, ainda no ensino secundário, passem por uma especialização. Assim, os estudantes timorenses que optarem pela via Ciências e Tecnologias, não terão acesso a disciplinas do componente Ciências Sociais e Humanidades, e vice-versa. Ao pensarmos em um currículo constituído por dois caminhos paralelos, percebe-se uma separação ou fragmentação entre as Ciências Sociais e Humanidades e os conteúdos das Ciências da Natureza.

Como já dissemos, a construção curricular do ESG se deu principalmente pelas instituições portuguesas responsáveis e teve pouca participação dos timorenses. Diante dessa situação, problematizamos como os elementos da ciência e da tecnologia são trabalhados nesse contexto?

Segundo Ramos e Teles (2012), o ministro da educação de Timor-Leste tinha considerado que a estruturação do plano curricular, assim como a elaboração dos programas das disciplinas, dos manuais para os alunos e dos guias para os professores deveriam ser em articulação com professores timorenses.

Estes grupos formados por professores timorenses passariam a ser denominados de equipes homólogas. No entanto, fatores como a carência de meio de comunicação, a falta de conhecimento na área específica e de Língua Portuguesa e a dificuldade do ministério timorense efetivar a constituição das equipes homólogas, fizeram com que essas equipes não fossem constituídas. Sem participação dos professores timorenses, é possível problematizar, os limites da configuração desse plano curricular, quando pensamos na influência do modelo do currículo português, composto por aspectos usados em sociedades ocidentalizadas e, principalmente, industrializadas que na maioria das vezes não reflete a realidade timorense.

\footnotetext{
${ }^{1}$ A disciplina Educação Física e Desporto não é oferecida no $12^{\circ}$ ano do ESG.
} 
Conforme Ramos e Teles (2012), apenas nas missões posteriores em Timor-Leste, e a pedido da Universidade de Aveiro, o Ministério da Educação selecionou professores timorenses para participarem em reuniões de trabalho com os membros das equipes de autores do currículo do ensino secundário. No entanto, essa seleção foi fortemente condicionada, pois só foram chamados professores do distrito de Dili (capital do país).

Apesar de ser um país pequeno, tendo por volta 1.200.000 habitantes, sua riqueza cultural é imensa, pois nos 400 anos de colonização portuguesa, pouco ou quase nada foi feito, além do extrativismo das riquezas, como o sândalo. Para se ter uma ideia, desde a chegada dos portugueses em 1512, apenas em 1915, surge a primeira escola oficial. Existem cerca de 32 línguas maternas no território, o Português ainda é pouco falado, apenas cerca 17 a $25 \%$. Em relação aos professores, segundo o censo de 2010 , cerca de $75 \%$ não têm formação acadêmica, os livros são extremamente raros e necessários nesse país. Por conta disso, consideramos no mínimo preocupante construir um currículo para o Timor-Leste, sendo que os poucos professores que participaram dessa reestruturação curricular, atuavam apenas no contexto da Capital Díli, pois há grande oposição entre o campo e a cidade.

Segundo Ramos Gonçalves (2012), os livros escolares e estratégias pedagógicas utilizadas para a aprendizagem da/em Língua Portuguesa nas escolas têm sido elaborados sem conhecimento das realidades locais e das características do Tétum (língua nativa falada em mais $90 \%$ do território timorense) e omitem aspectos importantes das histórias de TimorLeste, decorrente da muito provável falta de conhecimentos dos estrangeiros sobre o país.

Martins (2014), que coordenou a implementação do currículo no ESG, afirma que a equipe portuguesa procurou aprofundar conhecimentos sobre a realidade timorense e a cultura, inclusive a cultura escolar, mas não foi possível situar o mesmo nível de participação das equipes timorenses. Segundo a mesma autora, "o fenómeno da globalização atingiu praticamente todos os setores de atividade humana e o desenvolvimento curricular é um deles" (MARTINS, 2014, p. 23).

Num outro ponto do texto, autora afirma que:

Também será necessário olhar para os resultados 'a partir de dentro', por oposição a visões 'colonizadoras'. A educação em ciências em Timor-Leste, seguindo padrões internacionais, é um propósito mais isso não dispensa o seu enquadramento numa perspectiva multicultural, num mundo que é plurilíngue. (MARTINS, 2014, p. 23, grifo nosso)

Apesar dessa fala inicial da coordenadora do grupo que elaborou o ESG e autora desse texto em questão, dizendo que há oposição a visões colonizadoras, na segunda frase há uma contradição quando diz que segue padrões internacionais sem dispensar a multiculturalidade. Sem explicitar ou aprofundar o que afirma, fica difícil compreender o que significa os padrões internacionais. Essa afirmação da autora nos remete ao que Quijano (2006) aponta como três formas de colonialidade do saber/poder:

1) a dominação por meios não exclusivamente coercitivos, mas naturalizando o imaginário cultural europeu como forma única de relacionamento com a natureza, com o mundo social e com a própria subjetividade;

2) eliminação das muitas formas de conhecer, próprias dos nativos de uma região, e sua substituição por outras novas formas, que serviram aos propósitos civilizadores do regime colonial: violência epistêmica com relação às outras formas de produção de conhecimentos, símbolos e modos de significação, a partir de uma europeização cultural que se tornou aspiração, sedução e suposto caminho de acesso ao poder; 
3) a suposta geração de conhecimentos que elevam em si uma pretensão de objetividade, cientificidade e universalidade.

O Plano Curricular do ESG (2011) encerra com uma reflexão breve sobre metodologias de ensino e a listagem de um conjunto de condicionantes de execução do projeto, com vista a chamar a atenção das autoridades timorenses para questões de índole prática e estratégica, que deverão ser levadas em conta com vista à obtenção dos melhores resultados possíveis ao nível da implementação da reforma preconizada. Entre esses condicionantes, destacamos a formação de professores.

De acordo com esse documento, o Ministério da Educação de Timor-Leste deverá assegurar a todos os professores a oportunidade de seguir uma formação adequada para poderem elevar a qualidade do seu desempenho profissional, de modo, a garantir uma oferta formativa de base sólida nas áreas de "Ciências e Tecnologias" e "Ciências Sociais e Humanidades". Nessa perspectiva, o Plano do Ministério da Educação (2013-2017) destaca que a formação de professores para atuarem nessas duas áreas é uma ação vista como primordial para o desenvolvimento do país.

Sobre as condições essenciais para o sucesso da reestruturação curricular, o Plano Curricular do ESG (2011) destaca que o governo precisa dar a devida importância à elaboração de manuais escolares para alunos e guias didáticos para os professores, mostrando empenho em procurar fontes de financiamento para a sua publicação e meios adequados para a sua distribuição. Nessa perspectiva, para a reestruturação curricular, também se torna importante a produção de programas das disciplinas escolares para todos os anos do ciclo de estudos. Esses documentos foram elaborados pelos professores portugueses e entregues ao Ministério de Educação em Timor-Leste em 2012.

De acordo com Sangreman (2012), uma das preocupações em relação à operacionalização dos novos manuais das disciplinas estaria relacionada à realidade vivenciada pelos professores timorenses. Esses docentes foram formados no período em que o país estava sob domínio da Indonésia, só conhecendo os termos técnicos das disciplinas em bahasa indonésia e não em português, Por esta razão, é necessário uma formação docente visando prepará-los para desenvolverem nas salas de aula do ensino secundário os manuais propostos.

Ramos e Teles (2012) afirmam que as questões como a escolha do português como língua de ensino, o desenvolvimento de novos currículos adaptados ao contex to timorense ou a capacitação dos docentes para o ensino, continuará a revelar-se crucial em documentos posteriores, surgindo como uma linha de ação insistentemente trilhada nesse país.

Segundo Pereira e Fernandes (2013), relatam um pouco de suas dificuldades atuando na formação de professores timorenses, na condição de cooperantes brasileiros em Timor-Leste, num contexto em que os materiais do novo currículo já estavam sendo implementados em muitas salas de aula do Ensino Secundário timorense, inclusive na Escola de Ensino Secundário Geral XII de Novembro, a qual atuaram com projetos temáticos:

Com isso, percebemos ser frequente as discussões, e até certas dificuldades, com relação a temática energia. Por exemplo, alguns professores, principalmente os de Física, alegavam que essas dificuldades tinham suas origens em questões da linguagem, pois em bahasa indonésio, língua na qual a maioria deles havia sido alfabetizada, e que ainda pauta alguns dos materiais mais utilizados nas aulas de ciências, a palavra (e logo o conceito) energia é apresentado como sinônimo de eletricidade (PEREIRA; FERNANDES, 2013, p. 6). 
Para esses autores, as relações de sentidos eram imediatas e a dificuldade era sempre justificada pelo conceito se apresentar de maneira contraditória, em ambas as línguas, indonésia ou portuguesa.

Nessa perspectiva, Martins e Ferreira (2013, p. 22) ao afirmarem que a "transferência entre diferentes culturas, contextos [...] de ideias, propostas e ou recursos didáticos é uma tarefa difícil e com muitos riscos", é no mínimo preocupante, pois a ideia de universalização e transferência de saberes está estritamente ligada à globalização e transnacionalização da educação, e, portanto há um silenciamento das culturas e possível dependência econômica, contrastando com processos emancipatórios.

\section{PROCESSOS DE COLONIALIDADE PELO CURRÍCULO}

Segundo o Plano do Ministério da Educação de Timor-Leste para o quinquênio 20132017, até o ano de 2015 será implementada a melhoria substancial da qualidade no ESG. Este documento prevê ainda que em 2015 será realizado a monitorização da implementação do Currículo do ESG. Assim estabelecido, cabe ao poder político timorense, face aos indicadores recolhidos e à constatação social dos desvios verificados entre a realidade existente e as metas definidas, a decisão sobre a reforma ou reestruturação curricular.

Diante disso,consideramos que a proposta curricular do ESG pretenda ser implementada "Ipsis litteris" nas escolas. No entanto, sabemos que a transmissão de significados e de proposições de um contexto a outro sempre está sujeita a deslocamentos de sentidos, pois a linguagem não é transparente.

Os documentos curriculares construídos principalmente pelos portugueses, não podem ser considerados como pacotes lançados pelo governo sobre as escolas, que irão consumi-los sem releituras, sem gestos de interpretação. Estes documentos sofrem várias interpretações num processo polissêmico, que são próprias do funcionamento da linguagem, pois esta, não os sentidos construídos podem não ser os mesmos para todos o tempo todo. Nessa perspectiva, apesar dos documentos oficiais, em seu conjunto, aspirar intervir no funcionamento dos demais contextos, essas orientações são interpretadas de diferentes maneiras nos contextos locais.

Se pensarmos, que esses fenômenos da linguagem ocorrem numa mesma língua, o que podemos pensar num país que possui a Língua Portuguesa como língua de ensino, onde a maioria é falante de Tétum? No contexto timorense ocorre um fenômeno linguístico que consiste na coexistência da Língua Tétum e da Língua Portuguesa como línguas oficiais. Além disso, essa conjuntura linguística não se resume ao binarismo oficial, pois o plurilinguismo das línguas maternas e das línguas de trabalho (inglês e indonésio) são desafios e disputas comunicacionais constantes nas ações político-educacionais.

Para complicar ainda mais essa questão, mesmo que a maioria ainda não fale a Língua Portuguesa ou a tenha como segunda língua, como seriam esses processos de produção de sentidos de construções pensadas a partir de sociedades ocidentalizadas?Eis outra questão que nos atravessa: a colonialidade do saber e a dominação pelo currículo ou ainda uma colonização curricular.

Fazendo nossas as palavras de Paulo Freire (1977, p. 20):

Fazia-se necessário que os estudantes guineenses estudassem, prioritariamente, sua geografia e não a de Portugal, que estudassem seus braços de mar, seu clima e não o Rio Tejo. Era preciso que os estudantes guineenses estudassem, prioritariamente, sua história, a 
história da resistência de seu povo ao invasor, a da luta por sua libertação que lhe devolveu o direito de fazer sua história, e não a história dos reis de Portugal e das intrigas da Corte.

A questão da colonialidade nesse contexto é marcante e pode ser observada numa transnacionalização do currículo, a qual é a "transferência" de certos conhecimentos pensados numa dada realidade, levada para outra sociedade sem levar em conta os conhecimentos locais, sem proporcionar um diálogo de saberes. Podemos refletir que essas podem ser formas atuais do colonialismo europeu. Até os brasileiros em situação de cooperação internacional, mesmo não fazendo parte da Europa, mas possuindo inúmeras influências colonialistas e de colonialidade do poder e saber (CASTRO-GÓMEZ; GROSFOGUEL, 2007) podem cair nessa armadilha, como apontam Pereira, Cassiani e Linsingen (2015, p. 213) num artigo em que abordam o PQLP:

Precisamos urgentemente discutir aspectos de etnocentrismo invertido, lembrando as dificuldades enfrentadas pelos brasileiros em sua educação em um país estrangeiro. Temos que falar sobre aspectos do tratamento diferente dos estudantes do Norte (Europa e EUA) e Sul (África e Ásia), porque algumas vezes nos esquecemos que não somos europeus.

Enfim, essas questões devem ser tratadas como reflexos de um processo mais amplo, que partem do que algumas ideiais como globalização (e seus efeitos), além da transnacionalização do currículo, a educação assistencialista e o neocolonialismo, através da colonialidade do poder. Segundo Castro-Gomez e Grosfoguel (2006), é preciso imaginar alternativas utópicas descoloniaisanticapistalistas, em busca de autonomia dos professores.É preciso desnaturalizar a tradição seletiva trazendo conteúdos descolonizadores que contem outras histórias, os conflitos, os equívocos, problematizando conhecimentos dados como verdadeiros, neutros e tácitos. Concordando com Michael Apple (1982), a cultura dominante escolhe como importantes determinados significados e práticas, ao passo que outros são negligenciados e excluídos.

\section{A IMPLEMENTAÇÃOO DO CURRÍCULO DE ESG}

Felizmente implementar um currículo não se trata simplesmente de transferir os sentidos presentes no currículo oficial para a sala de aula, como se a linguagem fosse transparente. Os sujeitos interagem com as diferentes informações em que estão imersos. A matriz, que marcou a reestruturação curricular do ESG, emergiu de três grandes orientações:

- Elementos marcantes do desenvolvimento recente do sistema educativo timorense;

- Programas internacionais que tiveram a adesão do país (“Education for All” e "Objetivos de Desenvolvimento do Milênio");

- Realidade interna, na qual se inscrevem princípios normativos (Constituição da República, e Lei de Bases da Educação), princípios orientadores da ação (Política Nacional da Educação), reformas estruturais (Lei Orgânica do Ministério da Educação) e reforma do sistema de ensino (Reforma Curricular do Ensino Básico).

Porém, reconhecemos as diferenças que podem haver entre um currículo planejado e aquele que se pratica. Goodson (1995) faz críticas em se estudar somente à dimensão escrita do currículo, afirmando que o currículo escrito não passa de um testemunho visível, público e sujeito a mudanças, uma lógica que se escolhe para, mediante sua retórica, legitimar uma 
escolarização. Conforme esse autor, o currículo escrito é irrelevante para a prática (não provado), isso porque, existe muitas vezes dicotomia entre o currículo escrito e o currículo praticado.

Percebemos que a construção curricular do ESG se deu principalmente pelos portugueses, num movimento de cima para baixo.Tomando como base as ideias do ciclo contínuo ou a abordagem do ciclo de políticas, proposto por Stephen Ball e Bowe (1992), podemos pensar diferente a forma como vem sendo implementado o currículo do ESG.De acordo com esses autores, o ciclo de políticas é composto por três contextos: o contexto da influência, o contexto da produção de textos e o contexto da prática. $\mathrm{O}$ contexto de influência é caracterizado pelo momento em que se produzem definições e discursos políticos. $\mathrm{O}$ contexto da produção de textos diz respeito ao contexto no qual o texto da política é produzido. Enquanto que o contexto da prática corresponde às práticas dos profissionais que atuam nas instituições de ensino. Neste contexto, a política é recriada por processos de recontextualização, ou seja, não são simplesmente implementadas, mas estão sujeitas à interpretação e a serem "recriadas".

Conforme Ball (2001), as reformas não se prendem simplesmente à introdução de novas estruturas, mas também exigem e trazem consigo novas relações, culturas e valores. Nessa perspectiva, o processo de traduzir as políticas curriculares em prática se faz de uma maneira bastante complexa e não linear. Assim, as políticas são produzidas em um processo circular, de modo que os múltiplos contextos e os diversos discursos vão sofrendo constantes processos de ressignificações, hibridizações e recontextualizações.

Para Ball (2001), transformar a modalidade da palavra escrita para a modalidade da ação é algo difícil e desafiador. Durante o processo de leitura e implementação, as políticas curriculares passam por inúmeras ressignificações, ou seja, no momento em que as instituições de ensino buscam responder e adequar-se às políticas de currículo, estas ganham novos sentidos.

Ao pensar nas relações entre o currículo escrito e o contexto da prática, Lopes (2005) lança o conceito de recontextualização por hibridismo. Esse termo é fruto da articulação entre o conceito de recontextualização (BERNSTEIN, 1996) e o conceito de hibridismo (CANCLINI, 1998).

A recontextualização por hibridismo auxilia na interpretação da contínua circulação e fragmentação de variados textos e discursos no corpo social da educação. A partir desse conceito, é possível compreender a relação entre a reestruturação do currículo de Biologia do ESG de Timor-Leste e as ações que vem sendo desenvolvidas nas escolas timorenses.

Partindo do princípio de que o currículo é uma construção social, recorremos aos trabalhos de Ivor Goodson (1995), o qual destaca a necessidade de pesquisas que analisem a construção social dos currículos. Nessa visão, o currículo é entendido como uma arena de todos os tipos de mudanças, interesses e relações de dominação. $\mathrm{Na}$ medida em que a elaboração de um currículo é um processo que envolve escolhas e interesses, as lutas e os conflitos são quase inevitáveis. Nessa perspectiva, esse autor propõe a adoção de estudos históricos-sociais-construcionistas para investigar a construção social do currículo.

No território timorense, consideramos imprescindível elucidar o contexto histórico, social, político e econômico em que se desenvolveu o currículo do ESG. De acordo com Apple (1999), os primeiros estudos sobre o currículo ocorrem fortemente atrelados ao aspecto social, envolvendo, inclusive, questões de controle e de poder. Esse autor propõe que nas escolas seja transmitido "o conhecimento de todos nós", em vez de somente o "conhecimento da elite". 
Dewey (2007), por sua vez, afirma ser necessário que conteúdos do currículo escolar valorizem os interesses e as experiências de vida dos alunos, tendo em vista um processo contínuo e ativo que faça sentido para a vida atual e não como uma preparação apenas para o futuro.

Nesse sentido, é importante explorar assuntos que muitas vezes estão fora do currículo tradicional, o que está relacionado com a crítica de Michael Apple (1999). Segundo esse autor, o currículo nunca é apenas um conjunto neutro de conhecimentos que, de algum modo, aparece nos textos e nas salas de aula de uma nação. Pelo contrário, é sempre resultado da seleção de alguém, da visão de um grupo acerca do que seja conhecimento legítimo, ou seja, o currículo "é produto das tensões, conflitos e concessões culturais, políticas e econômicas que organizam e desorganizam um povo" (APPLE, 1999, p. 59).

\section{CONSIDERAÇÕES FINAIS}

Consideramos que não se pode ser simplesmente implementar um currículo, como um "pacote" pronto e acabado. Há resistências, diferentes interpretações, necessidades de formação contínua, um diálogo com a formação inicial. Num país com tantas demandas, em que os livros são tão escassos, pensar em jogar fora o bebê junto com a água do banho, seria muito desanimador. Algumas saídas que temos encontrado para uma construção mais coletiva:

- Formação de grupos ${ }^{2}$ de pesquisa da UNTL, entre os brasileiros e timorenses, baseando-nos em leituras e práticas freirianas, pensando a descolonização do saber;

- Discussões com os futuros professores de ciências sobre a ciência e a tecnologia, de forma mais crítica e contextualizada, sem desprezar os manuais, os quais são tão raros em TL.

Nesse sentido, as discussões nesses grupos são embasadas por reflexões epistemológicas da Ciência e Tecnologia e por Estudos Sociais da Ciência e da Tecnologia (ESCT) latino-americano, além da sociologia da tecnologia como âmbito privilegiado de produção de sentidos sobre as profundas imbricações socioculturais. (LINSINGEN et al., 2014).

Ao nos depararmos com a fragmentação e a descontextualização do currículo existente em Timor-Leste, enfatizamos a necessidade de aprofundar aspectos da transnacionalização do currículo e a importância de estudos de descolonização do saber e as epistemologias do sul.

Concordamos com Mignolo (2003) que enfatiza que não se deve negar a importância dos saberes ocidentais hegemônicos, mas sim regionalizar e provincializar as diferentes histórias locais (modernidades coloniais) e os diferentes projetos globais (colonialismos modernos). Segundo o autor, é preciso demonstrar que esses projetos são circunscritos nos limites das diferenças coloniais específicas na formação do sistema moderno colonial.

Nesse sentido, enfatizamos a importância dos professores timorenses desenvolverem sua autonomia docente, de forma que possam agir criticamente durante a sua atuação, relacionando os conteúdos do currículo exótico, com os conhecimentos tradicionais, de forma que os conteúdos científicos signifiquem, além de valorizar a cultura e a identidade timorense.

\footnotetext{
${ }^{2}$ O Grupo Ensino de Ciências e Tecnologia na Educação (GEECITE) foi formado com o objetivo de desenvolver um projeto do Programa de Mobilidade Internacional, financiado pela CAPES, sob a coordenação das professoras Suzani Cassiani e Patrícia Giraldi da Universidade Federal de Santa Catarina; dos professores timorenses Gaspar Varela e Estanislau Correia da Universidade Nacional de Timor Lorosa'e; e da Cooperante do PQLP Fátima Suely Cunha. Participam desse grupo estudantes de licenciatura das Ciências da natureza.
} 
A educação científica e tecnológica emancipatória e mais condizente com os interesses e necessidades do país, pode ser uma alternativa na formação de professores.Assim, o ensino de ciências deixa de ser enfocado em conteúdos distantes e fragmentados, baseados em conhecimentos científicos supostamente neutros e passa a ser enfocado em situações vividas pelos educandos em seu cotidiano.

Nossas reflexões nos mostram a necessidade de aprofundar aspectos da transnacionalização do currículo e a importância de estudos de descolonização do saber, para que possamos construir saídas mais emancipadoras.

\section{REFERÊNCIAS}

CHANG, T. et al..A study of an augmented CPFR model for the 3C retail industry. Supply Chain Management: Na International Journal, v.12, n.3, p, 200-209, 2007.

APPLE, M..A política do conhecimento oficial: faz sentido a ideia de um currículo nacional? In: MOREIRA, A. F.; SILVA, T. T. (Orgs.) Currículo, cultura e sociedade. 3. ed. São Paulo: Cortez, 1999.

BALL, S. J.. Diretrizes políticas globais e relações políticas locais em educação. Currículo sem Fronteiras, v. 1, n.2, p. 99-116, 2001.

BALL, S. J.; BOWE, R..The policy processes and the processes of policy. In: BALL, S. J., Bowe, R.; GOLD, A. (Orgs.). Reforming education and changing schools: case studies in policy sociology. Londres/Nova Iorque: Routlegde, 1992.

BERNSTEIN, B.. A estruturação do discurso pedagógico: classe, códigos e controle. Petrópolis: Vozes, 1996.

CANCLINI, G. N.. Culturas híbridas. São Paulo: EDUSP, 1998.

CASTRO-GÓMEZ, S.; GROSFOGUEL, R.. El giro decolonial: Reflexiones para uma diversidad epistêmica más alládel capitalismo global. Bogotá: SiglodelHombre Editores, 2007.

DEWEY. J.. Democracia e Educação: capítulos essenciais. São Paulo: Ática, 2007.

FREIRE, P. Cartas à Guine Bissau:Registros de uma experiência em processo. Rio de Janeiro: Editora Paz e Terra, 2. ed., 1977.

GOODSON, I..Currículo: Teoria e História. Petrópolis, Rio de Janeiro: Vozes, 1995.

LINSINGEN, I. et al.. Educação CTS em Timor-Leste: Possibilidades e Desafios. Revista Científica Multidisciplinar da Sociedade Timorense. n.1, p.51-51, 2014.

LOPES, A. C.. Política de currículo: recontextualização e hibridismo. Currículo sem Fronteiras, v.5, n.2, p.50-64, 2005.

MARTINS, I. P.; FERREIRA, A. A Reestruturação Curricular do Ensino Secundário Geral em Timor-Leste. Um caso de cooperação da Universidade de Aveiro no domínio da educação.In: MORAIS, C.; COIMBRA, R. L. Coimbra (Coords.). Pelos mares da língua portuguesa. Aveiro: Universidade de Aveiro, 2013, p. 97-110. 
MARTINS, I. Educação em ciências no ensino secundário geral em Timor-Leste: da investigação à cooperação. Journal of Science Education, n.14, p. 20-23, 2013.

MIGNOLO, W. D.. Histórias locais/Projetos globais. Belo Horizonte: Editora da UFMG,2003

PÊCHEUX, M.. O Discurso: estrutura ou acontecimento. 4. ed. Campinas: Pontes, 2006.

PEREIRA, P., CASSIANI, S., LINSINGEN, I. V. International educational cooperation, coloniality and emancipation: the Program Teacher. Revista Brasileira de Pós-Graduação, v. 12, n. 27, 2015.

PEREIRA, P., FERNANDES, F. Condições de produção de uma aula de energia: a formação científica de professores em Timor-Leste. Atas do IX Encontro Nacional de Pesquisa em Educação em Ciências, Águas de Lindóia, 2013.

QUIJANO, A. Colonialidade do poder e classificação social. In: SOUSA SANTOS, B.; MENESES, M. P. Epistemologias do Sul. São Paulo: Cortez, 2010. p. 84-144

REPÚBLICA DEMOCRÁTICA DE TIMOR-LESTE. Ministério da Educação.Plano Curricular do Ensino Secundário Geral. 2011. Disponível: <file:///C:/Users/Brazil/Desktop/PlanoCurricularV2.pdf \. Acesso em: 12 abr. 2015

REPÚBLICA DEMOCRÁTICA DE TIMOR-LESTE. Ministério da Educação.Plano do ministério da educação 2013-2017.2012. Disponível em: $<$ http://planipolis.iiep.unesco.org/upload/Timor-Leste/Timor leste_Ministerio_da_Educacao_Plano_2013-2017.pdf.Acesso em: 12 abr. 2015.

RAMOS, A. M.; Teles, F.. Memória das políticas educativas em Timor-Leste: A consolidação de um sistema (2007-2012). Aveiro: Universidade de Aveiro, 2012.

RAMOS GONCALVES, M. A Língua Portuguesa e o conflito intergeracional em TimorLeste. In R. Teixeira E Silva, Y. Qiarong, M. Espadinha \&A. Leal (Eds.), IIISIMELP: A formação de novas gerações de falantes de português, no mundo China, Macau: Universidade de Macau. 2012

SANGREMAN, C.. .As Boas Práticas na Cooperação para o Desenvolvimento na Educação, o Caso da Universidade de Aveiro. II Coopedu - África e o Mundo, 2012.

SOUSA SANTOS, B.; MENESES, M. P. Epistemologias do Sul. São Paulo: Cortez, 2010. 